\title{
A INTERAÇÃO ENTRE OS CONHECIMENTOS DE UM PROFESSOR ATUANTE E DE UM ASPIRANTE COMO SUBSÍDIO PARA A APRENDIZAGEM DA DOCÊNCIA
}

\section{Knowledge exchange by an experienced teacher and an inexperienced one as an aid in learning how to teach}

\author{
Marcos Daniel Longhini ${ }^{1}$ \\ Dácio Rodney Hartwig ${ }^{2}$
}

\begin{abstract}
Resumo: A presente pesquisa traz alguns resultados obtidos com base em um processo de parceria entre um professor com experiência profissional docente e um professor aspirante, tendo o pesquisador como mediador. Toma-se, como eixo para análise, a 'base de conhecimentos para o ensino' de Shulman (1987), e como contexto para coleta dos dados, a elaboração, implementação e análise de um conjunto de aulas de Ciências dedicadas às séries iniciais do Ensino Fundamental. Os resultados apontam que a justaposição de professores não garante a troca de todo e quaisquer tipos de conhecimentos, até mesmo porque, dependendo do momento profissional em que o docente se encontra, são diferentes suas necessidades e a forma como se interpreta e dá significado à sua prática.
\end{abstract}

Palavras-chave: Formação docente. Professor aspirante. Professor atuante. 'Base de conhecimentos para o ensino'. Ensino de Ciências.

\begin{abstract}
This research presents results obtained from a partnership between a veteran teacher, a teacher-to-be and the researcher, who acted as the mediator. The 'knowledge base of teaching' by Lee Shulman was the reference for analysis and the context, within which data was collected, and included the elaboration, implementation and analyses of a series of Natural Sciences Classes for the lower grades of Elementary School. The results point out that putting teachers together does not ensure complete or even partial exchange of knowledge, because teachers' needs and the way they interpret and focus on their professional practice depend on their professional momentum.
\end{abstract}

Key words: Teacher education. Unexperienced teacher. Experienced teacher. 'Knowledge base of teaching'. Science teaching.

\footnotetext{
${ }^{1}$ Doutor em Educação; professor adjunto, Faculdade de Educação, Universidade Federal de Uberlândia (FACED/UFU). Uberlândia, MG. < mdlonguini@yahoo.com.br>

${ }^{2}$ Doutor em Educação; professor, Programa de Pós-graduação em Educação, Universidade Federal de São Carlos (UFSCar). São Carlos, SP. <hartwig@ufscar.br>
}

\footnotetext{
${ }^{1}$ Universidade Federal de Uberlândia (FACED/UFU/MG)

Av. João Naves de Ávila, 2121 - Campus Santa Mônica Uberlândia, MG

38.408-100 


\section{Formação de professores e os saberes docentes}

Nas últimas décadas, houve um crescente número de pesquisas acerca da formação de professores, sendo que, no Brasil, conforme aponta Giovanni (1998), esta temática é relativamente nova; vem ganhando força a partir da década de 1980. Desponta, neste cenário, um novo tipo de pesquisa, em contraposição àquelas em que os docentes eram vistos como meros executores técnicos, chamadas pesquisas 'processo-produto'.

Segundo Gauthier et al. (1998), a partir da década de 1970, começou-se a perceber que a ação do professor poderia influenciar na aprendizagem dos alunos, e que nem tudo era predeterminado por condições externas, como, por exemplo, o talento dos estudantes ou os programas instrucionais. A partir da década de 1980, portanto, com o olhar centrado no papel do professor, pesquisas começaram a apontar para a existência de um 'repertório de conhecimentos' específicos à profissão docente.

Essas pesquisas passaram a analisar os saberes específicos da docência, os chamados 'saberes docentes'. Estes, segundo Borges e Tardif (2001), tornaram-se uma possibilidade para a análise dos processos de formação e profissionalização do professor.

Tais saberes nem sempre são aprendidos em cursos de formação docente, uma vez que se considera que eles podem também ser gerados no dia-a-dia da prática profissional, além de outras instâncias, como a família, o círculo de amigos etc. Porém, nem sempre os saberes adquiridos na experiência tiveram relevância nos processos de formação docente. Voltando um pouco no contexto histórico da formação de professores, Queiroz (2003) aponta que os saberes têm sido trabalhados de modo estanque, um se sobrepondo ao outro, ou seja, ora foi dado maior destaque aos saberes disciplinares, ora aos pedagógicos, sendo que os oriundos da experiência têm sido aqueles que receberam menor ênfase. Para Lelis (2001), a literatura da área influenciou a 'curvatura da vara', conferindo à prática uma instância de produção de saberes, em contrapartida à valorização de uma hegemonia puramente teórica.

Dentro deste contexto, um dos autores que busca apresentar um rol de saberes específicos à profissão docente é Shulman (1987). O pesquisador se dedicou a investigar docentes novatos e experientes e pesquisar, por exemplo, como é o processo em que a pessoa se torna professor. Ele investigou casos de docentes considerados exemplares, com base nos quais buscou extrair comportamentos, formas de agir, posturas a serem ensinadas ou possivelmente ensinadas a futuros professores. A este rol de conhecimentos essenciais à profissão, o pesquisador designou de 'base de conhecimentos para o ensino'.

Segundo Shulman (1987), ela é constituída por um agregado de conhecimentos e habilidades. Se fosse para organizar um 'manual' acerca do que o professor deveria saber para ensinar, o pesquisador aponta que este deveria contemplar, no mínimo, os seguintes conhecimentos: conhecimento do conteúdo a ser ensinado; conhecimento pedagógico geral, o qual inclui os amplos princípios e estratégias de gerência e organização da sala de aula; conhecimento do currículo, com particular compreensão acerca de programas e materiais necessários ao ofício de professor; conhecimento pedagógico do conteúdo, que é um amálgama entre o conteúdo específico a ser ensinado e pedagogia; conhecimento do aluno, o qual inclui suas características gerais; conhecimento do contexto educacional, o qual implica conhecer diversos aspectos do local ou região onde a escola está inserida, suas normas de funcionamento, as comunidades que a freqüentam e suas culturas, e conhecimento dos fins 
educacionais, o qual inclui conhecer os propósitos educacionais e as bases históricas e filosóficas em que estão apoiados.

Como apontado anteriormente, um elemento que não pode ser desconsiderado, quando se pensa na constituição de um rol de conhecimentos necessários aos professores, é a influência que a prática cotidiana oferece, por se tratar de um trabalho rico e complexo. Segundo Tardif (2002), os professores produzem ou tentam produzir, em seus contextos de trabalho, saberes que eles compreendem e dominam, saberes da experiência, que, segundo Lima e Reali (2002), tendem a se converter em habitus, rotinas, ou 'saberes tácitos', segundo Zeichner (1993).

Tardif (2002, p. 56) afirma que "trabalhar não é exclusivamente transformar um objeto ou situação numa outra coisa, é também transformar a si mesmo no e pelo trabalho". Deste modo, se uma pessoa ensina durante trinta anos, ela não faz simplesmente alguma coisa sobre algo, mas alguma coisa sobre si mesma. Portanto, o trabalho modifica o trabalhador e sua identidade, que, com o passar do tempo, modifica, por conseguinte, o modo de trabalhar.

O rol de conhecimentos da docência modifica-se, portanto, no decorrer da prática profissional, o que implica que, além dos conhecimentos adquiridos no processo de formação inicial, o docente incorpora outros tantos ao seu fazer profissional.

\subsection{O início da docência e a interação entre pares}

Se a aprendizagem se dá durante toda a vida, que papel seria reservado aos cursos de formação 'inicial' de professores? Para Moura (2003), a formação do sujeito é contínua, e não é possível identificar um marco zero. Segundo o autor, se ele existisse, seguramente seria o momento em que nascemos.

Adams e Krockover (1997) e Cusati (1999), dentre outros, afirmam que os professores iniciantes, quando vão para sala de aula, carregam visões do que é ser professor, previamente adquiridas durante seu período enquanto alunos, tanto na Educação Básica quanto na Superior.

Esse conjunto de crenças implica sérias conseqüências para sua formação e,portanto, para os próprios cursos de licenciatura. Segundo Tardif (2002), as rotinas com as quais professores agem na prática são percebidas pelos novatos, quando ingressam na profissão, como certezas profundas, resistindo ao exame crítico do que aprenderam durante a formação inicial, podendo perdurar muito além dos primeiros anos de atividade docente. Segundo o mesmo autor, a formação acadêmica, na maior parte das vezes, não consegue abalá-las e muito menos transformá-las. Bejarano (2001) emprega a metáfora de um 'filtro', que os professores em início de carreira usam para separar aquilo que lhes parece pertinente, do que fora aprendido nos cursos de formação.

A formação inicial, que muitas vezes despreza toda a bagagem de conhecimentos e experiências que o futuro professor traz, não é suficiente para gerir a complexidade da sala de aula. Isso faz com que, quando o professor recém-formado ingressa na prática, na maior parte das vezes, depare-se com situações com as quais não sabe trabalhar, ou sente que o curso não o preparou para a realidade, conforme cita Conti (2003). Na ausência de alternativas, segundo Carvalho (1992), acaba usando práticas 'aprendidas' na condição de aluno, com seus ex-professores - mesmo se anteriormente rejeitasse muitas delas. 
Por outro lado, a este professor em início de carreira é requerido que resolva situações num ambiente complexo, como a sala de aula. Nesse momento, entram em cena estratégias de sobrevivência, que, conforme aponta Conti (2003), podem variar em função do tempo de experiência e da idade do docente. Segundo o autor

Os mais experientes tendem a servir-se de 'estratégias de dominação', que envolvem controle, alto grau de exigência etc; os professores mais jovens aproveitam-se da idade para se aproximar dos alunos, uma vez que, por conta disso, há uma grande afinidade de gostos, interesses, referências culturais etc. (CONTI, 2003, p. 118)

Para García (1992), os professores mais experientes têm problemas e preocupações diferentes dos principiantes. Segundo aponta o mesmo autor, em análise da obra de Picke, os professores evoluem, durante a carreira, de uma concepção mais técnica da profissão para uma visão mais científica e filosófica; de uma preocupação com a sobrevivência para uma preocupação com os outros; de uma imitação dos 'superiores' para a criação de um estilo próprio.

Veenman (citado por Cusati, 1999) aponta alguns problemas que acometem os professores em início de carreira. A indisciplina e a motivação dos alunos estão entre os mais sérios; a primeira pelo fato de os jovens professores ainda não possuírem procedimentos estruturados para lidarem com a classe, e a segunda devido à dificuldade em lidarem com diferenças individuais dos alunos. Também são citadas, pelo autor, as dificuldades de os docentes iniciantes lidarem com: meios audiovisuais, os pais, a comunidade, atividades de avaliação, além de possuírem uma elevada preocupação com a própria competência, centrando mais a atenção em si próprios do que nos alunos. Mediante tais dificuldades, classificam a atividade docente como física e mentalmente cansativa.

A falta de apoio aos docentes em início de carreira, tanto por parte das escolas, quanto pelas próprias instituições que os formou, também é um aspecto problemático, conforme mostra Mizukami (1996). Segundo a autora, os resultados de um estudo de caso com cinco participantes apontaram que todos passaram por uma trajetória solitária de desenvolvimento profissional. Este é, em especial, um dos momentos em que o professor iniciante mais precisa de auxílio, tratando-se de um período de insegurança e falta de confiança em si mesmo, conforme exemplifica García (1992).

A partilha de experiências entre pares e a assessoria prestada por colegas de trabalho podem ser um ponto de apoio neste processo. Tais iniciativas vão ao encontro do que apontam Tardif (2002), Imbernón (2002) e de resultados positivos de experiência realizadas, dentre outros autores, por André (1997), Dias-da-Silva (1998), Nascimento (2002), Valençuela (2002) e Montalvão e Mizukami (2002). Tardif (2002) indica que a partilha de experiências é uma fonte de aprendizagem para o trabalho docente e exemplifica tal tipo de situação por meio de uma fala de um professor a respeito da influência dos pares na formação: "no que se refere realmente à sala de aula, quem me ensinou realmente as coisas foram meus colegas à minha volta. Meus melhores professores são eles" (TARDIF, 2002, p. 87).

Portanto, apoiando-se na idéia de partilha de experiências entre pares como recurso para formação docente, e considerando que professores em estágios diferentes de suas vidas profissionais construíram diferentes saberes acerca da docência, esta pesquisa parte da hipóte- 
A interação entre os conhecimentos...

se de que é possível que professores com estas características possam aprender elementos necessários à docência quando colocados em situação de parceria.

Deste modo, esta pesquisa tem como questão central: em que aspecto e de que forma um professor atuante e um aspirante, trabalhando conjuntamente em seu processo de formação, contribuem entre si na construção de conhecimentos necessários para o ensino, tendo como mediadora a participação de um professor formador? (pesquisador)

\section{$2 \mathrm{O}$ desenvolvimento da pesquisa}

Os dados foram obtidos por meio da contribuição de duas professoras e sua coleta foi realizada durante o segundo semestre de 2003. Uma delas, Vânia, com 18 anos de experiência docente, designamos de 'professora atuante'. A outra, Jocimara, sem nenhuma experiência deste tipo, chamamos de 'professora aspirante'. Ambas eram alunas do curso de Licenciatura em Pedagogia, de uma instituição particular de uma cidade do interior do estado de São Paulo.

Mediante a compreensão acerca das novas exigências para formação do professor de Educação Infantil e séries iniciais do Ensino Fundamental, houve procura por formação em nível superior por parte de docentes possuidores da habilitação específica para o magistério em nível médio - o que justifica o fato de um mesmo curso ser freqüentado por alunos egressos do Ensino Médio, como era o caso de Jocimara, mas também de professores em exercício, como Vânia.

A escolha das duas professoras deu-se por dois aspectos centrais: primeiramente, atendendo ao requisito principal da pesquisa, ou seja, licenciandos que possuíssem distintos níveis de experiência como professor. Outro aspecto que consideramos foi a disponibilidade de tempo para as reuniões, que ocorreram semanalmente durante aquele semestre.

O mote para analisar que conhecimentos eram intercambiados entre as professoras e de que forma isso se dava foi a organização de um conjunto de aulas acerca de uma temática relacionada à área de Ciências, campo de atuação dos pesquisadores. Essas aulas, posteriormente, deveriam ser implementadas, o que na verdade foi feito com os alunos de Vânia, professora de uma $2^{a}$ série do Ensino Fundamental de uma escola pública de Educação Básica.

No decorrer do processo, o pesquisador atuou de maneira participativa no desenvolvimento do trabalho junto às docentes, inserindo-se nas discussões em grupo, contribuindo com textos ou materiais para elaboração das aulas, acompanhando as implementações em sala de aula, discutindo e avaliando os resultados juntamente com as professoras. Essa demanda se tornou mais forte no decorrer das reuniões, uma vez que as participantes requisitavam sua opinião, questionavam suas dúvidas e esperavam por sugestões de atividades acerca do tema.

Pautávamos por uma orientação construtivista de ensino ao planejarmos as atividades, em que os alunos deveriam ser considerados elementos centrais, seja porque suas idéias deveriam ser respeitadas e utilizadas, seja porque as crianças seriam agentes diretos em seu processo de aprendizagem.

O tema das aulas foi escolhido pelas participantes em nossos encontros iniciais, os quais eram realizados em sala reservada, em horário em que não possuíam atividades do curso de graduação. Tomou-se como tema o "ar e suas características", por se tratar de um assunto que Vânia deveria desenvolver com seus alunos, na ocasião. 
Organizamos um total de cinco aulas sobre o tema. A primeira, ministrada por Vânia, foi dedicada a um levantamento acerca das idéias dos alunos sobre o assunto em questão. A segunda aula, ministrada por Jocimara, foi dedicada ao estudo de duas características do ar: sua existência e seu peso. A seguinte, conduzida pela professora atuante, foi dedicada a mais dois aspectos a respeito do ar: sua utilização como reagente para o fogo e seu aquecimento, resultando na mudança de sua densidade. A quarta aula, ministrada por Jocimara, foi dedicada à elaboração de um registro, por parte dos alunos, das atividades realizadas. Conduzida por Vânia, a quinta e última aula foi utilizada para fins de avaliação.

As aulas, apesar de terem sido implementadas na sala onde Vânia atuava, ocorreram de modo intercalado pelas duas participantes, conforme apontamos anteriormente. Optamos que a implementação das aulas não se daria em conjunto pelas participantes, para que as mesmas pudessem trocar impressões e tecerem análise sobre as atividades realizadas somente no momento das reuniões, o que facilitava o registro, também, por meio de videotape.

Todas as aulas foram registradas em videotape e a gravação era levada para análise conjunta com a professora aspirante, processo em que era submetida a críticas e ajustes. As gravações das aulas foram realizadas pelo próprio pesquisador, sendo que, nesses momentos, não interferia no processo, deixando a cargo das professoras o desenvolvimento do que havia sido planejado nas reuniões conjuntas.

Ao final de todo processo de coleta dos dados, essas gravações foram transcritas para que pudéssemos verificar em que momentos e em relação a que situações as professoras necessitavam trocar mais informações entre si.

Além de tais dados, ao final do processo, realizamos uma entrevista com cada uma das professoras, de modo a levantar mais elementos que apontassem a possível contribuição do par no decorrer do processo realizado. As questões versavam sobre os momentos de maiores dificuldades enfrentadas por elas, e sobre onde e de que forma haviam buscado apoio; além de explorarmos de que forma a crítica ou sugestão do par influenciava a reestruturação das aulas seguintes.

\section{Resultados obtidos: conhecimentos em jogo}

Mediante análise dos dados expressos pelas professoras nas entrevistas realizadas, assim como daqueles obtidos nos processos de elaboração, implementação e análise de suas aulas, apontamos quais foram as principais fontes ou experiências, acerca da profissão, vividas pelas docentes, como elas influenciaram as participantes durante o processo, além, é claro, dos principais conhecimentos expressos pelos participantes, dentre os apontados na 'base de conhecimentos para o ensino' de Shulman (1987).

Jocimara, mesmo não possuindo experiência como professora, revelou conhecimentos pedagógicos gerais, provavelmente, oriundos de sua vivência prévia como estudante. Com base neles, avaliava, por exemplo, atividades que seriam mais ou menos estimulantes para os alunos. Também estiveram presentes, em diversos momentos, sugestões de atividades pautadas em práticas realizadas por ex-professores seus, como, por exemplo, quando sugeriu uma prática com objetivo de manter a disciplina dos alunos: 
Jocimara: "Você já fez a dinâmica da caixa para eles descobrirem o que tem dentro da caixa? Você comeşa na segunda-feira e só abre a caixa na sexta-feira se eles se comportarem."

Alguns ex-professores, principalmente na infância, ofereceram a Jocimara exemplos de formas de agir que ela acreditava que deveriam ser transmitidos aos alunos. Além disso, a infância pobre e as dificuldades na época escolar, aliadas a docentes que a auxiliaram justamente nos momentos mais críticos, parecem ter influenciado sua maneira de pensar e de exercer o ensino:

Jocimara: "O financeiro na minha educaşão sempre influenciou muito. Por conta de ter sempre de trabalhar, às vezes en chegava para o professor: - olha, en não tive como fazer este trabalho hoje, porque eu era babá na época, depois foi loja, tudo mais. Os professores sempre quebravam um galho [...] O professor era sempre muito amigo!"

Esta influência se mostra na ênfase que ela deu aos fatores afetivos na relação entre professor e aluno, presentes durante suas aulas:

"[...] eu vejo que a amizade faz, tudo entre professor e aluno. Não tentar só levar em sala de aula a disciplina, mas tentar um relacionamento, assim... o que acontece fora, e aí, como está na sua casa, como foi seu final de semana? Levar também pelo lado emocional! Vamos supor, segunda-feira trabalhar como foi seu final de semana, professor contar como foi o dele, uma integração bem familiar em sala de aula".

Para Vânia, os exemplos e crenças pautados em seus professores também pareceram estar presentes em sua mente. Porém, diferentemente da professora aspirante, muitas dessas crenças foram avaliadas e reestruturadas mediante sua prática cotidiana. Em relação àquelas que possuía no início da carreira, a professora atuante revelou que as mudanças de postura foram ocorrendo durante os anos de experiência. Segundo ela, o aspecto que mais se modificou em sua trajetória profissional foi sua forma de trabalhar com os alunos:

Vânia: "Eu via assim: o aluno era uma criança que não sabia nada e que ia para escola e só ia aprender o que você passava. Você ia ser o centro, sabe? Ele ia ter que escutar, ter que aprender o que você ia ensinar. Ele ia aprender só com você [...] Naquela época eu não achava que as experiências que eles tinham eram válidas. Eu achava que eu era mais importante, assim como eu achava minhas professoras super importantes!"

A experiência profissional em sala de aula parece ter permeado a maior parte dos conhecimentos que Vânia expressou durante nossas reuniões e, também, durante suas aulas. Os anos de experiência propiciaram a ela reconhecer outros aspectos atrelados à aprendizagem, como, por exemplo, o afetivo:

Vânia: "Tem momento que eu não acho que eu tenho que exercer meu papel de trabalhar conhecimentos com eles. É uma hora de eu dar carinho, é a hora de vocêp pegar no colo mesmo, sabe? Hoje, assistindo um filme, teve um que veio se aninhando no meu colo. Sabe, e você vê esta carência que eles têm. Então o professor não é mais aquele que passa conhecimento, transmite conhecimento. Ele tem que trabalhar toda 
Longhini, M. D.; Hartwig, D. R.

parte emocional, afetiva, de saúde mesmo com as crianças [...] Estas experiências são coisas que você acarreta pro resto da vida."

Muitas dessas aprendizagens sobre a docência estão relacionadas a sua própria vida enquanto pessoa, oriundas de experiências vividas e que vão além das paredes da sala de aula. De sua experiência cotidiana, são muitos os elementos em que se apóia e que proporcionam a constituição de novos conhecimentos, como, por exemplo, o próprio fato de ser mãe. O contato diário com os alunos também lhe proporcionou um rol de conhecimentos que são constantemente modificados, mediante as diferentes situações que vivencia.

Vânia: "Olha, muito que me ajuda... eu acho assim: eu ser mãe já é uma coisa que ajuda na escola, hoje nos dias de hoje, eu acho. Muita coisa você entende. A minha própria idade, por exemplo! Eu acho que você vai se tornando mais ponderada, coisa que você era mais enérgica, que tinha que ser daquele jeito... Hoje não! Você não conquista mais um aluno levando a ferro e fogo. Você tem que ser mais maleável. Você nunca deve bater de frente com aluno porque você nunca vai ganhar. Eu acho que é o dia-a-dia. Acho que todo dia você aprende uma coisa, e toda aprendizagem vai te somando."

Os dados também apontaram que ambas as professoras possuíam um insuficiente conbecimento do conteúdo especifico acerca do tema que iriam ensinar, demonstrado por meio das respostas ingênuas aos problemas que surgiam nos momentos de discussão. As dificuldades em relação a esse conhecimento se mostraram presentes desde a seleção de atividades das aulas (uma vez que elas não selecionavam aquelas em que apresentavam dificuldades), até inquietações ocorridas nos momentos de organização dos experimentos, quando elas próprias buscavam aprender o que não sabiam para poderem ensinar, conforme apontam os diálogos abaixo:

Vânia: "O ar existe? Como você sabe que o ar existe? (pergunta para Jocimara)

Jocimara: Porque eu respiro ele!

Vânia: E como você sabe que você respira o ar?

Jocimara: Porque todo mundo fala! (risos)

$[\ldots]$

Jocimara: Pode colocar outra questão nesta aula: e se o ar acabasse?

Vânia: Se o ar acabasse não estava nem conversando, estava tudo morto! (risos)

Pesquisador: "E se o ar deixasse de existir, o que aconteceria? A gente morreria, e o que mais?

Jocimara: [...] até as plantas! Nada existiria! Até uma árvore respira!"

Em alguns momentos, elas paravam e se inquietavam com suas próprias dúvidas, recorrendo também ao pesquisador para esclarecê-las:

Vânia ao pesquisador: "Eu acho assim... nos outros planetas existe ar?

Jocimara: De onde vem esse ar?! (pergunta em tom enfático)

Vânia: Saturno, Mercúrio tem o ar? O que é atmosfera?" 
De modo a suprir tais carências, uma das fontes utilizadas durante quase todo o processo foram os livros didáticos de Ciências, utilizados por alunos de $2^{a}$. série do Ensino Fundamental. Esporadicamente, como ocorreu com Jocimara, recorriam às memórias daquilo que fora aprendido na escolarização básica, ainda que conhecimentos insipientes.

Uma das mais importantes fontes de informações e, até mesmo, de segurança foi o próprio pesquisador, como mostra a fala de Vânia na ocasião em que decide mudar o tema das aulas pelo fato de poder contar com um auxílio maior:

Vânia: “[...] Pensei, pensei e acho que deveria mudar [...] e eu também não teria muita dificuldade de trabalhar outro tema. Eu queria muito, já que a gente vai trabalhar, aproveitar, não é assim? Eu acho que esse aqui (mostra o tema "ar" no livro) é mais completo, dá experiência. E acho que, por exemplo, na hora de dar experiências, você não vai estar junto? Você vai poder?” (pergunta ao pesquisador)

A necessidade de aprender o que não sabiam ganhou força à medida que foram percebendo, no decorrer do contato das aulas, que os alunos também possuíam idéias aprimoradas do assunto, além daquelas com que elas esperavam se deparar, conforme aponta o diálogo travado no momento de análise de uma aula de Vânia pelo grupo:

Jocimara: "Têm umas respostas fora também!

Pesquisador: Respostas de que tipo?

Jocimara: Muito fora! Mas também parece que eles (os alunos) sabem mais do que imaginava!

Vânia: Tem hora que tem lógica o que eles falam.

Jocimara: Tem $[\ldots]$ "

Episódios também evidenciaram que a busca e intercâmbio de conhecimentos do conteúdo especifico, pelas professoras, nos momentos das reuniões, resultaram numa ampliação e melhoria no nível de conhecimento do assunto a ser abordado, refletidas no momento em que ministravam suas aulas. Muitos desses conhecimentos eram aprendidos no momento da aula, às vezes até mesmo com os próprios alunos, conforme evidencia o diálogo, abaixo, em que as professoras comentam sobre um estudante que explicou a respeito dos primeiros vôos em balões utilizando animais:

Jocimara: "Agora en falo que para uma 2a. série está bom demais! Se eles aprenderam bem até aí, tudo bem, porque, sinceramente, nem eu sabia tudo isso! (sobre o tema ar)

Vânia: E é aquilo que eu falei para o Marcos: esta história dos três animais, nem eu sabia! Na hora do copo, lá, da fumaça, que era o gás carbônico, en também não sabia [...]

Jocimara: E naquela época que eu estudava era também só no livro!

Vânia: Olha aqui onde eles acharam dos animais! (mostra o livro didático) [...] e eu pedi para eles irem lá na frente ler; eles foram lá ler! Foi um pato, um galo e um carneiro que eles colocaram no balão e voltaram vivos."

Para ambas as professoras, a carência que possuíam acerca de tais conhecimentos prejudicava a forma com que elas entendiam e agiam frente às respostas dos alunos. Isso se 
mostrou presente quando uma criança levantou uma hipótese na prática em que uma vela acesa era envolvida por um copo: ela sugeriu que a vela fosse cortada em um pedaço menor, uma vez que, sendo longa, ficaria muito próxima ao fundo do copo quando este fosse invertido sobre ela; portanto, a chama se apagaria rapidamente. A professora experiente acatou a sugestão e assim o fez, mas a novata, ao assistir à cena, não atentou para o fato de se tratar de uma hipótese do aluno e de um processo e construção do conhecimento. Nenhum comentário foi feito pelas participantes a respeito do fato, cabendo ao pesquisador comentar sobre a iniciativa do aluno.

O processo mostrou que, apesar de muitos dos conhecimentos científicos sobre o tema serem incorporados à aula, isso não conseguiu suprir, totalmente, as dificuldades que as professoras tinham em conteúdos de Ciências, permanecendo muitas de suas concepções distantes das consideradas científicas.

O conhecimento pedagógico geral, o qual inclui um conjunto de conhecimentos acerca do gerenciamento da prática profissional, foi um dos mais intercambiados em todos os momentos do projeto, sobretudo no quesito 'disciplina dos alunos'. A professora aspirante, por exemplo, buscava formas de contornar suas dificuldades para organizar e distribuir as atividades no transcorrer do tempo que lhe fora disponibilizado. Em outros momentos, apontou dificuldades em saber como organizar e gerenciar as atividades e os alunos em sala, conforme indica sua fala:

Jocimara para Vânia: “[...] depois você vai ver ali (na gravação) que eu quis aconchegá-los (alunos) num círculo só de carteiras, entendeu? Porque minha idéia era fažr a experiência do balão no meio deles, mas não deu! Só se eu matasse trinta para parar [...] Até aí eu estava super segura, até achando: Nossa! Como eu estou indo bem!

Vânia: Estava com a bola cheia! (risos).

Jocimara: Eu estava sentindo realmente que eu tinha capacidade, mas a partir do momento que eu vi que os alunos não se sentavam, que eu não conseguia arrumar as carteiras, eu juro por Deus que en queria sair pela porta e nem entregar a atividade dos balões! O que eu faço?

Vânia: Eu não quis, ontem, desanimar. Eu pensei: deixa ela tentar [...] É válido como experiência, mas en tinha certeza que aquela disposição de carteiras não ia funcionar!"

Este parece ter sido um elemento de mais fácil intercâmbio entre elas, conforme demonstra a fala de Jocimara, quando tenta empregar formas de conter a indisciplina dos alunos com base em estratégias observadas na aula de Vânia:

Pesquisador: "E se você, Vânia, estivesse naquele momento ali como ela, como você agiria? (quando os alunos não paravam sentados)

Vânia: Eu mandaria todos sentarem. Todos viram? Então aguardem [...]

Jocimara: Mas eu tentei fazer isso! Eu não consegui!

Pesquisador: Você até conseguiu no começ, mas depois eles foram saindo devagar e você ficou ilhada no meio deles. Tinha aluno que não via nada!

Jocimara: E sabe, um determinado momento, o que eu ia faz̧er, mas eu falei: não, agora o Marcos está filmando. O que eu ia fazer? Eu ia dar um belo de um berro, en ia sentar e fazer como a Vânia fez! Usar o mesmo método que ela faz, mas eu falei: ele está filmando, e aí vai demorar muito." 
Durante o transcorrer de todas as reuniões, Vânia também expressou conbecimentos pedagógicos gerais, quando teceu comentários sobre o gerenciamento das atividades durante as aulas, as características dos alunos e o funcionamento da escola. Contrariamente a alguns aspectos em que Jocimara enfrentava dificuldades, a professora atuante mostrava ter um domínio maior, como: o gerenciamento do tempo de duração das atividades, a organização dos alunos em sala, o emprego de estratégias com estudantes indisciplinados, a proposição de formas de avaliação, dentre outros.

Vânia: "Eu acho que assim: a minha parte teórica teria que durar mais que 50 minutos, porque até você colocar eles em grupo (alunos), até você passar o que você quer e eles começarem a pesquisar, e en pesquisar, eles são mais demorados [...] Deveria ter assim, duas aulas de 50 minutos [...] você reúne em grupo, ai você já vai ver quanto tempo você vai perder. E a hora que eles começarem a pesquisar você corta a aula? Sabe, eu acho que no Ensino Fundamental, eu acho que não é como uma aula que você fala rapidamente e as crianças já vão captando e se você cortou, no outro dia você continua e tudo bem. Aí a outra aula que você vai começar, assim, até você organiz̧ar de novo, eles até esqueceram o que você falou. Tem que ser diferente."

As características dos alunos foram um dos aspectos mais discutidos pelas professoras, conforme citamos anteriormente, sobretudo em relação ao controle da indisciplina. Vânia, durante nossas reuniões, explicava a Jocimara sobre o comportamento dos alunos, suas histórias de vida, seus interesses e suas dificuldades. O contexto da escola, suas características e normas de funcionamento também foram elementos que permearam diversos momentos das discussões, especialmente nas ocasiões de análise das aulas, quando assistiam às gravações das atividades. Vânia era a principal fonte de informações acerca do conhecimento do contexto educacional. Ela conhecia o comportamento de cada aluno, e sabia como eles agiam em sala, conforme expressa sua fala abaixo:

Vânia: "Hoje, por exemplo, esses dois alunos (Carlos e Émerson), eles estão, assim, dificicis de serem trabalhados. Você viu o comportamento, não tem como! O Carlos sem o Émerson é uma coisa; - Carlos com o Émerson, ele ganha força. O Émerson é líder negativo e ele leva os outros. O Euler também ele leva, o resto não. O Carlos segue o Émerson e o Émerson precisa chamar um, porque ele já tem a malandragem e ele não quer levar sozinho. Então se ele for para a diretoria, alguém tem que ir junto com ele.

$[\ldots]$

Jocimara assistindo à gravação: Olha esse daí! Que vontade de dar um soco" (risos).

Vânia: Tadinho, ele está com tanto problema [...]

Jocimara: Por que, Vânia?

Vânia: Porque a mãe pegou o pai na cama com outra e separou. Eles foram todos para casa da tia. Até o remédio que en comprei, porque ele estava macbucado, cheio de ferida, não estão mais passando."

O conhecimento pedagógico do conteúdo é um amálgama de conteúdos específicos a serem ensinados com estratégias acerca de como ensiná-los. Este tipo de conhecimento é de 'propriedade exclusiva' do professor, uma vez que ele é responsável pela sua elaboração no momento da prática. Apesar de a forma de desenvolver o conteúdo na aula ser de inteira 'autoria' do 
professor, percebemos elementos incorporados em suas práticas que puderam ter origem no processo de interação ocorrido em nossas reuniões.

Isso se mostrou, sobretudo, quando discutimos que as respostas não deveriam ser oferecidas pelos alunos, e sim, que estes deveriam pensar no problema proposto com base na prática. No princípio, as professoras insistiam que os problemas deveriam ser propostos e que as respostas 'certas' deveriam ser trabalhadas. O diálogo a seguir mostra, por exemplo, como Vânia aproveitava as idéias dos alunos para lançar novos questionamentos:

Vânia: "Olha, o Fernando disse que no balão tem tudo saquinho de areia e que quando épara o balão subir, joga fora o saquinho de areia. E quando está lá no ar e quer descer e não tem saquinho de areia? Aluno: Só o ar quente faz, o balão subir [...]

Vânia: Mas o que tem a ver o ar quente com o ar frio?"

$[\cdots]$

Os dados mostraram que este conhecimento está intimamente relacionado com o conbecimento do conteúdo específico. As dificuldades expressas pelas professoras, nos conteúdos específicos de Ciências, repercutiram, em diversos momentos, nas possibilidades acerca de como ensiná-los. Apesar disso, houve possibilidades de discussão acerca da forma com que desenvolveram suas aulas.

Os livros didáticos, além de serem um de seus suportes na busca por aprenderem mais sobre o conteúdo científico, também as auxiliaram na busca por atividades sobre como ensinar aquele conteúdo, ou seja, foram empregados também como fonte de sugestões que acabaram influenciando na forma de desenvolver as atividades em aula, ou seja, no conbecimento pedagógico do conteúdo.

Durante as reuniões, houve momentos em que o pesquisador interferiu, sobretudo quando se notava que elas não conseguiam avançar além do livro didático, não oferecendo novas possibilidades para desenvolver o tema. As inserções do pesquisador também se deram em momentos em que levava montagens de experimentos que ofereciam possibilidades de trabalhar o assunto, além de ter organizado as práticas que efetivamente foram utilizadas na escola. Isto ocorreu, por exemplo, quando o pesquisador sugeriu trabalhar com uma questão relacionada a balões:

Pesquisador: "E aquela (pergunta) do por que o balão sobe?

Jocimara: Porque é outro tipo de oxigênio, né? É outro tipo de ar!

Pesquisador: Não, aqueles balões, já viu balão com cesto?

Jocimara: Pela pressão do ar do fogo, não é? Do ar quente!

Pesquisador: $O$ ar quente! $O$ ar quente é mais leve que o ar frio! Tem uma experiência super bonita que você pode fazer com um copinho e uma vela, que ele enche de ar quente e sobe (como uma gangorra)

Vânia: Olba, veja como eu achava, eu não sabia. Eu achava que queimava o ar, acabando com o ar lá dentro!" 
A interação entre os conhecimentos...

Além da prática citada anteriormente, o pesquisador perguntou a elas se conheciam o experimento sobre combustão do ar, utilizando um copo e uma vela. Apesar de conhecerem a prática, não souberam a explicação para o fenômeno:

Pesquisador: "Ah, sabe aquela experiência que a gente inverte o copo sobre o fogo?

Vânia: Como?!

Pesquisador: Põe uma vela e se você inverte um copo sobre ofogo [...]

Jocimara: [...] apaga.

Pesquisador: Ele "consome" o oxigênio...

Vânia: Eu achava que queimava e acabava.

Pesquisador: Na verdade, ele faz uma reação, onde transforma oxigênio em gás carbônico. E esse gás que fica ali dentro do copo está mais quente."

O somatório destes fatores deve ter sido o que levou Vânia a afirmar que, 'em relação ao que fora desenvolvido dentro da sala de aula', o pesquisador havia sido sua maior fonte de conhecimentos.

De forma geral, podemos dizer que das categorias de conhecimentos empregadas neste trabalho, e que constituem a 'base de conhecimento para o ensino', quase todas estiveram presentes nos momentos das reuniões, expressas sob as mais diversas formas. Algumas estiveram mais presentes nas falas de Vânia e, outras, nas de Jocimara. Porém, a professora atuante, mesmo com experiência profissional, vivenciou uma atividade que nunca havia desenvolvido, e isto fez com que recorresse à ajuda. Jocimara também necessitou trocar diversas idéias de modo a sanar dúvidas, estipular caminhos, amenizar medos.

Deste modo, muitos dos conhecimentos que estiveram em jogo na etapa de planejamento das atividades geraram dúvidas para ambas as professoras, especialmente aqueles relacionados ao conhecimento do conteúdo específico.

O processo revelou que ambas as professoras emitiam opiniões e críticas acerca das aulas de seu par, sobretudo acerca de conhecimentos pedagógicos gerais. Jocimara, por exemplo, tecia críticas acerca da organização dos alunos na sala, propondo, até mesmo, formas de punir os indisciplinados. Tais idéias, apesar de serem ouvidas por Vânia, nem sempre eram pacificamente aceitas, uma vez que a professora atuante as filtrava com base em sua prática cotidiana, orientando Jocimara sobre o que realmente poderia surtir efeito e o que fugia à realidade, segundo sua concepção.

Outro aspecto que se mostrou presente nas discussões para elaboração das aulas foi o conhecimento do conteúdo específico. Enquanto organizavam as atividades, as professoras também testavam, entre si, seus conhecimentos, e buscavam aprender para poderem ensinar.

Vânia também serviu como ponto de apoio a Jocimara quando esta buscou trocar informações que amenizassem a má impressão que havia tido da profissão, que trouxessem a ela um sentimento de tranqüilidade, o qual parecia ter perdido em sua primeira aula. Deste modo, Vânia também a auxiliou com apoio emocional.

Jocimara também teceu críticas sobre aspectos pedagógicos da aula de Vânia, por exemplo, no momento em que a professora atuante realizava os experimentos com os alunos, e muitos não enxergavam a prática por estarem numa posição desfavorável. Para Vânia, Jocimara ofereceu alguns novos olhares sobre situações as quais ela nunca havia percebido, cons- 
truções introjetadas no decorrer de sua vivência profissional. Tais idéias ofereceram elementos para que ela pudesse repensar sua própria prática.

Um aspecto que também analisamos foi como a participação do pesquisador afetou o processo de reflexão conjunta. Os dados mostraram que, enquanto a relação entre Jocimara e Vânia girava em torno dos conbecimentos pedagógicos, em relação ao pesquisador, a contribuição parecia estar relacionada ao conhecimento do conteúdo especifico. Elas não percebiam situações em que estava em jogo um frutífero desenvolvimento de conhecimentos pedagógicos do conteúdo, por exemplo, quando Vânia conduzia amplas discussões com os alunos sobre o conteúdo. Jocimara atentava para outros aspectos da aula, os quais eram significativos para ela, como, por exemplo, a saída dos alunos da sala ou a forma com que se comportavam na aula.

\section{Considerações finais}

A experiência mostrou que nem tudo pode ser aprendido num processo de interação, nem mesmo com auxílio de um mediador. No caso de Jocimara, mesmo buscando ensaiar com Vânia um roteiro para suas aulas, a prática revelou uma diversidade de situações antes não previstas. Os dados demonstraram que o contato próximo de Jocimara com Vânia não garantiu à primeira a riqueza de detalhes sobre o cotidiano da sala de aula, quanto a própria vivência deste espaço.

É importante ressaltar, também, que a relação entre elas nem sempre se deu de forma amistosa. Apesar de Vânia ouvir críticas e sugestões de Jocimara, nem sempre elas eram pacificamente aceitas, uma vez que a professora atuante as filtrava com base em sua prática cotidiana, orientando Jocimara acerca do que realmente podia ou não ser feito, na prática.

Ambas as professoras eram seletivas no aproveitamento das idéias de seu par, mas acreditamos que o critério de seleção era diferente para cada uma. A professora atuante, em sua história de vida profissional, seguramente havia testado muitas de suas idéias; nesse momento de sua carreira, seu crivo centrava-se na seleção das idéias que poderiam oferecer uma melhor aprendizagem aos seus alunos.

Apesar de Vânia ter explicado acerca de aspectos que, segundo ela, geravam dificuldades durante as aulas, Jocimara mostrava a necessidade de fazer e vivenciar sua própria história, de testar suas teorias pessoais, mesmo mediante exemplos contrários, constantemente apontados por Vânia. Talvez as dificuldades e limitações apontadas pela professora atuante fizessem mais sentido para ela própria, pois eram originadas em seu contexto, sua história. Jocimara ainda tinha necessidade de vivenciá-las e, deste modo, muitos dos saberes de Vânia, ou foram ressignificados, ou foram ignorados.

Além disso, em muitos momentos, elas pareciam possuir enfoques diferentes, a serem observados na gravação das aulas. Em diversas circunstâncias, percebíamos que Jocimara observava as imagens buscando atentar para sua atuação como professora, enquanto Vânia atentava para seus alunos, seus comportamentos e atitudes. Deste modo, nem sempre a condição de desigualdade entre níveis de experiência indica que a interação e troca de conhecimentos serão acentuadas, podendo, ocorrer, em certas situações, o inverso.

Vânia, que poderia alertar sobre situações que já havia vivenciado, e que poderia oferecer elementos indicando melhores possibilidades, também se mostrou inibida, em certos 
A interação entre os conhecimentos...

momentos, de tolher a iniciativa de seu par, deixando, até mesmo, que ela aprendesse com os próprios erros. Tanto Vânia quanto Jocimara deixaram transparecer um certo receio em tecer críticas um à outra, talvez com medo de serem mal interpretadas ou criarem qualquer indisposição. As críticas, quando ocorriam, eram apontadas de modo tímido, até mesmo expressas pelo tom de voz que usavam nessas ocasiões.

Em suma, o processo acenou para a direção de que a justaposição de professores não garante a troca de todo e quaisquer tipos de conhecimentos. Os dados mostraram, inclusive, que acolher uma opinião ou idéia de um par parece estar mais atrelado a fatores intrínsecos de quem se propõe a realizá-la, do que a fatores extrínsecos, como o auxílio de um colega experiente, o que pôde ser evidenciado pela recusa de Jocimara em realizar algumas atividades sugeridas por seu par. Os dados da entrevista final também apontaram que certas idéias não haviam sido expressas nas reuniões conjuntas, o que demonstra que a interação entre os conhecimentos parece não se dar pela simples reunião de pares.

A experiência mostrou que o pesquisador, atuando como mediador, teve um papel fundamental em alguns aspectos. Sem sua atuação para apontar diversos aspectos da prática docente, as professoras limitavam-se a trocar conhecimentos naquilo que sentiam dificuldades ou para elas gerava tensão, medo etc. Perdiam oportunidades de entenderem o processo de construção de conhecimento pelos alunos, mediante as sugestões que eles próprios davam, isso seguramente devido ao insuficiente conhecimento do conteúdo científico que estavam trabalhando.

A tarefa de aprender a ensinar, primordial nos cursos de formação, parece estar permeada por diversos fatores, sendo que alguns deles fogem, até mesmo, do âmbito do curso de formação inicial. A aprendizagem com base na prática, experiência relatada nesta pesquisa, indica que tais iniciativas não devem ser desprezadas nos cursos de formação, mas ser analisadas com cautela.

\section{Referências}

ADAMS, P. E.; KROCKOVER, G. H. Beginning Science Teacher Cognition and It's Origins in the Preservice Secondary Science Teacher Program. Journal of Research in Science Teaching, Hoboken, New Jersey, v. 34, n. 6, p. 633-53, 1997.

ANDRÉ, M. E. D. A. O papel mediador da pesquisa no ensino de didática. In: OLIVEIRA, M. R. N. S. (Orgs.). Alternativas do ensino de didática. Campinas: Papirus, 1997. p. 19-36 (Coleção Prática Pedagógica).

BEJARANO, N. R. R. Tornando-se professor de Física: conflitos e preocupações na formação inicial. 2001. 300f. Tese (Doutorado) - Faculdade da Educação, Universidade de São Paulo, São Paulo, 2001. 
Longhini, M. D.; Hartwig, D. R.

BORGES, C.; TARDIF, M. Apresentação. Educação \& Sociedade, Campinas, v. 22, n. 74, p. 9-26, 2001.

CARVALHO, A. M. P. Reformas nas licenciaturas: a necessidade de uma mudança de paradigma mais do que de mudança curricular. Em Aberto, Brasília, INEP, ano 12, n. 54, abr/jun, 1992. p. 51-64.

CONTI, C. L. A. Imagens da profissão docente: um estudo sobre professoras primárias em início de carreira. 2003. 177f. Tese (Doutorado) - Faculdade de Educação, Universidade Estadual de Campinas, Campinas, 2003.

CUSATI, I. C. Aprendendo a ensinar Matemática no exercício da profissão: um estudo das fases inicial e final da carreira docente. 1999. 158f. Dissertação (Mestrado) - Programa de Pós-Graduação em Educação, Universidade Federal de São Carlos, São Carlos, 1999.

DIAS-DA-SILVA, M. H. G. F. O professor e seu desenvolvimento profissional: superando a concepção do algoz incompetente. Cadernos CEDES, Campinas, v. 19, n. 44. p. 33-45, 1998. Disponível em: <http:www.scielo.br>. Acesso em: 20 mar. 2003.

GARCÍA, C. M. formação de professores: novas perspectivas baseadas na investigação sobre o pensamento do professor. In: NÓVOA, A. (Org.). Os professores e a sua formação. Lisboa: Dom Quixote, 1992. p. 51-76.

GAUTHIER, C. et al. Por uma teoria da Pedagogia: pesquisas contemporâneas sobre o saber docente. Ijuí: UNIJUÍ, 1998. (Coleção Fronteiras da Educação).

GIOVANNI, L. M. Do professor informante ao professor parceiro: reflexões sobre o papel da universidade para o desenvolvimento profissional de professores e as mudanças na escola. Cadernos CEDES, Campinas, v. 19, n. 44, 1998. Disponível em: $<$ http:www.scielo.br>. Acesso em: 20 mar. 2003.

IMBERNÓN, F. Formação docente profissional: formar-se para a mudança e a incerteza. 3. ed. São Paulo: Cortez, 2002. (Coleção Questões da nossa Época, v. 77).

LELIS, I. A. Do ensino de conteúdos aos saberes do professor: mudança de idioma pedagógico. Educação \& Sociedade, Campinas, v. 22, n. 74, p. 43-48, 2001.

LIMA, S. M.; REALI, A. M. M. R. O papel da formação básica na aprendizagem profissional da docência (aprende-se a ensinar no curso de formação básica?). In: MIZUKAMI, M. G. N. ___ (Orgs.). Formação de professores, práticas pedagógicas e escola. São Carlos: EdUFSCar, 2002. p. 217-35.

MIZUKAMI, M. G. N. Docência, trajetórias pessoais e desenvolvimento profissional. In:___ _ REALI, A. M. M. (Orgs.). Formação de professores: tendências atuais. São Carlos: EdUFSCar, 1996. p. 59-91. 
A interação entre os conhecimentos...

MONTALVÃO, E. C.; MIZUKAMI, M. G. N. Conhecimentos de futuras professoras das séries iniciais do Ensino Fundamental: analisando situações concretas de ensino e aprendizagem. In: ___ REALI, A. M. M. R. (Orgs.). Formação de professores, práticas pedagógicas e escola. São Carlos: EdUFSCar, 2002. p. 101-126.

MOURA, M. O. O educador matemático na coletividade de formação. In: TIBALLI, E. F. A.; CHAVES, S. M. (Orgs.). Concepções e práticas em formação de professores. Rio de Janeiro: DP\&A, 2003. p. 129-145.

NASCIMENTO, M. R. Aprendizagem da docência: formação inicial, experiência docente e comprometimento profissional. 2002. 132f. Dissertação (Mestrado) - Programa de Pós-Graduação em Educação, Universidade Federal de São Carlos, São Carlos.

QUEIROZ, G. R. P. C. Didática e prática de ensino: aprofundando relações em tempos de mudança. In: SELLES, S. E.; FERREIRA, M. S. (Orgs.). Formação docente em Ciências: memórias e práticas. Niterói: Eduff, 2003. p. 105-116.

SHULMAN, L. S. Knowledge and teaching: foundations of the new reform. Harvard Educational Review, Cambridge, v. 57, n. 1, p. 1-22, 1987.

TARDIF, M. Saberes docentes e formação profissional. Petrópolis: Vozes, 2002.

VALENÇUELA, M. Os saberes que fundamentam a prática do professor. 2002. $142 \mathrm{f}$. Dissertação (Mestrado) - Programa de Pós-Graduação em Educação, Universidade Federal de São Carlos, São Carlos.

ZEICHNER, K. M. O professor como prático reflexivo. A formação reflexiva de professores: idéias e práticas. Lisboa: Educa, 1993.

Artigo recebido em janeiro de 2007 e aceito em julho de 2007. 